\title{
Redesign of the Introduction to Engineering Course and its Impact on Stu- dents' Knowledge and Application of the Engineering Design Process
}

\section{Dr. Haolin Zhu, Arizona State University}

Dr. Haolin Zhu received her PhD in Solid Mechanics and Computational Science and Engineering from Cornell University. She is currently part of the freshmen engineering education team in the Ira A. Fulton Schools of Engineering at Arizona State University. Currently she focuses on designing the curriculum for the freshman engineering program as well as the NAE Grand Challenge Scholars Program. She also designs and teaches courses in mechanical engineering at ASU. Her interests include innovative teaching pedagogies for increased retention and student motivation, innovations in non-traditional delivery methods, as well as structured reflective practices throughout the engineering curriculum.

\section{Dr. Benjamin Emery Mertz, Arizona State University}

Dr. Benjamin Mertz received his $\mathrm{Ph}$. D. in Aerospace Engineering from the University of Notre Dame in 2010 and B.S. in Mechanical Engineering from Rose-Hulman Institute of Technology in 2005. He is currently a part of a lecturer team at Arizona State University that focuses on the first-year engineering experience, including developing and teaching the Introduction to Engineering course. He also teaches Thermo-Fluids and High Speed Aerodynamics for the Mechanical and Aerospace Engineering Department at ASU. His interests include student pathways and motivations into engineering and developing lab-based curriculum. Recently, he has developed an interest in non-traditional modes of content delivery including online classes and flipped classrooms. 


\title{
Redesign of the Introduction to Engineering Course and its Impact on Students' Knowledge and Application of the Engineering Design Process
}

\begin{abstract}
This evidence-based practice paper describes the changes made to a 2-credit introduction to engineering course at Arizona State University to teach the engineering design process in the context of a semester-long project. The previous course design used the first half of the semester to teach important aspects of the engineering design process through scaffolding activities designed to highlight each step in the design process before having students apply those steps to a full design project in the second half of the semester. The new course design utilizes more justin-time learning strategies as students learn and apply the design process steps directly to their project as they work on the same project throughout the entire semester. To assess the impact that this course has on the students' knowledge and application of the engineering design process as well as potential benefits that may arise from the change in course structure, students were asked to critique a Gantt chart which described a flawed design process. This prompt was administered as a pre- and post-test during the fall 2015 semester. The results were coded according to 8 levels described in the literature related to this assessment technique: needs assessment/establishing design criteria; design context review; idea generation; analysis and decision-making; building and testing; overall layout of a design process and iteration; time allotments; and documentation. Results showed statistically significant increases in scores between pre- and post-tests at all 8 levels for the new course structure. The post-test scores were also compared to results from the same prompt administered in the spring 2015 semester, before the changes were made to the course, in order to compare the impact of the new course structure. The results showed a statistically significant increase in the overall critique scores as well as in the "Idea Generation" and "Building and Testing" levels. Based on these results, suggestions for course improvements will be made as well as insights into the use of scaffolding activities verses teaching the engineering design process in the context of a project will be discussed. Suggestions will also be made for further improvement of the assessment tool.
\end{abstract}

Introduction

Over the last few decades, freshman introduction to engineering courses have drawn the interest of many researchers. Many models for course structure and instruction have been proposed. One common trend is to emphasize the engineering design process and to incorporate "hands-on", team based projects in such a course ${ }^{1-5}$. While the scope and implementation of these projects vary between institutions, these types of projects in the first-year courses have been shown to improve both retention and learning ${ }^{6-9}$. What has been less studied is the extent to which the design process needs to be taught formally or scaffolded before being able to apply it to an openended project in a way that increases learning of the engineering design process ${ }^{10-11}$. 
At Arizona State University, the introduction to engineering course was re-engineered a few years ago to focus on the design process (giving students opportunities to apply the design process with design iteration), teamwork, communication skills, and it incorporated coursework that was linked to real-world multi-disciplinary engineering problems. The course structure that has been utilized involved two relatively independent parts. It began by introducing the engineering design process as well as basic engineering skills, tools, and software for the first 67 weeks, and ended with a 7-8 week multidisciplinary, hands-on, team design project. Students learned the concepts needed for the project during the first half of the semester, but they did not have to connect concepts from one unit to the next until the final design project in the second half of the semester. This structure was originally implemented to provide students with appropriate scaffolding to build skills before implementing these skills in a larger design project $^{10}$. While this approach did mix theoretical principles with hands-on activities which has been shown to improve student learning ${ }^{12}$, during the first half of the semester the labs consisted of mostly "task projects", as categorized by de Graaf and Kolmos ${ }^{13}$, where both the projects and the methods are mostly prescribed by the instructors. This strategy helps maintain focus within the course, but often does not produce as large of learning gains. Of specific concern is that students were taught the engineering design process during the second week of the class, but this was not applied to a complete design project until the second half of the class. It was noticed that students had a hard time applying or had little motivation to apply the practiced concepts from the earlier activities to their more open-ended design project. This transference issue was also noted by de Graaf and Kolmos ${ }^{13}$.

This course has recently been restructured to teach the design and project concepts in the context of a semester-long hands-on design project. All details and techniques of the engineering design process, as well as other basic engineering skills and tools, are introduced throughout the entire semester as they become useful in the design project. With the new structure, much more emphasis is placed on the engineering design process; more just-in-time learning would occur; and students are able to apply what they learn immediately in the context of the project. These elements of just-in-time learning and increased emphasis on a "discipline project" level project based learning strategy were added to the course in an attempt to increase student motivation to apply these fundamental design concepts in a manner that would improve their ability to apply them and transfer this knowledge into other contexts ${ }^{14-16}$.

To assess the effectiveness of these changes, the students' knowledge of the design process needs to be evaluated. Different instruments are available in the literature to assess different aspects of the engineering design process. For example, Carberry et al. ${ }^{17}$ developed an instrument to measure engineering design self-efficacy. McKenna and Hirsch ${ }^{18}$ developed a survey to measure students' confidence in engineering design. Other methods that have been used to measure students' knowledge and application of the design process include surveys, outcomes of design projects such as written reports and prototypes, interviews, student 
reflections, and responses to closed-ended or open-ended questions, etc. ${ }^{19-24}$. Unfortunately, many of these techniques are very time intensive to implement and analyze. In order to create a more efficient way to assess understanding of the design process, Bailey et al. ${ }^{25-26}$ developed a Gantt chart tool which shows a flawed proposed engineering design process and students' critique of the strengths and weaknesses of the proposed engineering design process are evaluated. This tool was used to assess students' knowledge and application of the engineering design process. Such a tool has been further developed and used in a freshman design based course by Saterbak et al. ${ }^{26}$. It has been found to be a valid and feasible option to assess and gain insights about the strengths and weaknesses of individual students' understanding of the engineering process at a detailed level in a freshman course and thus is chosen to be used to assess the impact of the new course structure.

The new course structure was implemented during the 2015 fall semester in 6 sections of the course, with approximately 40 students each, taught by the authors. Its impact on students' knowledge and application of the engineering design process has been assessed using a pre- and post-test discussed and used by Saterbak et al. ${ }^{27}$. Each time, students were asked to critique a Gantt chart that describes a 14-week schedule of a design project that has many flaws. More specifically, they were instructed to elaborate on the steps of the design process, discuss strategies appropriate to accomplish each step, and identify strengths and weaknesses of the proposed design process. A class taught using the old structure during the spring 2015 semester by one of the authors serves as a control group for the study. The same test was given to the control group during spring 2015 as a take home exam. Written critiques from each cohort were analyzed and evaluated using the rubrics created by Saterbak et al. at 8 levels: needs assessment/establishing design criteria; design context review; idea generation; analysis and decision-making; building and testing; overall layout of a design process and iteration; time allotments; and documentation ${ }^{27}$.

In this paper, details of the new structure of this course will be given and it will be compared to the old structure. Results from the pre- and post-test from the experimental group will be compared and discussed. Post-test results will also be compared between the experimental and the control groups. Insights about course structure and the effectiveness of the evaluation method as well as recommendations for future work will be given.

\section{Course Description}

The introduction to engineering course is a 2-credit course offered to mechanical, aerospace, electrical and chemical engineering majors in sections of 40 students. It meets twice a week for a 50 minute lecture and a 2 hour and 50 minute lab throughout the 15 -week semester. It introduces the engineering design process, basic engineering skills, and provides opportunities to learn about and use various engineering tools and software. The course also teaches basic written and oral communication skills important for communicating technical information effectively. 
Students also learn to work in a team environment, using design methods to address multidisciplinary real world engineering design problems. Specific learning objectives of this course are:

1. Students will, as part of a design team, use the engineering design process to create effective problem statements, and design, build, test, and analyze a prototype product that addresses realistic constraints and system requirements, while using basic project management techniques.

2. Students will use appropriate tools and software to collect and analyze data, to describe and predict the behavior of designs, and to justify design decisions based on appropriate models.

3. Students will apply basic teaming principles and team effectiveness practices, such as peer evaluation and role assignment, while working with their team.

4. Students will write a project report and give an oral/multimedia presentation following technical communication guidelines which include formatting, explaining and justifying aspects of the project.

5. Students will be able to identify their strengths and contributions, critique their own skills and understanding (lifelong learning), and develop identity as an engineer.

This paper mostly addresses the need to assess outcome number one. Students learn concepts during the lectures and engage in hands-on activities to practice and apply concepts learned during the labs in a makerspace. Multi-disciplinary teams are formed at the beginning of the semester and students stay in the same teams throughout the semester for various lab activities and for a hands-on design project.

In previous semesters, the engineering design process was introduced during the second week of class. All details of the engineering design process were given during one lecture, including specific techniques and design tools that can be used during different steps in the process. Examples of topics that were introduced during this lecture include design process heuristics, ideation techniques, decision matrices, functional decompositions, etc. Students practiced applying the engineering design process to solve a design challenge by coming up with a final conceptual design, based on a prompt given by the instructor, during the associated lab. After the second week, various engineering skills and tools were introduced during the lectures, such as, technical drawing, MATLAB, electrical fundamentals, motors and gears, etc. and students again had the opportunity to practice and learn by engaging in hands-on active learning activities during the labs. Topics such as electrical fundamentals and motors and gears were chosen to be discussed because the team hands-on design project chosen by the instructors often required such technical background. The hands-on design project was then introduced around week 7 and students were given a second opportunity to apply the engineering design process to a larger scale design problem which models a real world setting/problem. Students worked in teams to design, build, and test functional prototypes which solved the problem given. Examples of 
design projects that have been incorporated in the past include, a solar-powered vehicle design project, a renewable energy design project, an assistive technology design project, a waste sorter design project, a NAE (National Academy of Engineering) Grand Challenges design project, etc.

Even though students were able to practice applying the engineering design process twice throughout the semester using this old course structure (once during week 2 when the engineering design process was just introduced, and once during the second half of the semester by working on the hands-on design project) one common critique that often came up in the course evaluation survey was that students were not able to see the connections between topics introduced and they often had trouble applying what was learned during the first half of the semester in the design project. In addition, a lot of students often felt very rushed at the beginning of the project as they needed to go through quite a few steps in the engineering design process and came up with a proposed conceptual design within two weeks before moving on to the building and testing phase.

To this end, the authors have re-structured this course during the fall 2015 semester and applied this new course structure to 6 sections of this course taught during that semester. The entire course has been structured around the engineering design process and placed in the context of a design challenge. Table 1 shows weekly lecture and lab topics and a comparison between the two course structures.

An overview of the engineering design process was given during the second week of class and the hands-on design project was immediately introduced during the associated lab and students would begin defining the problem they were trying to solve (develop criteria and requirements based on documents describing the problem). In subsequent weeks, specific details and techniques about different steps in the engineering design process were introduced and students had the opportunity to apply them immediately by working on their hands-on design project during the associated labs. Other skills and tools were also introduced and practiced when they became necessary for the project. Topics such as electrical fundamentals and motors and gears were no longer introduced to students during lectures, instead, students conducted more extensive background research and were given opportunities to learn about these concepts on their own with guidance and resources during some of the labs. With the new course structure, a lot more details about the engineering design process were given to students and students were able to immediately apply them to the project. 
Table 1. Comparison of weekly lecture and lab topics

\begin{tabular}{|c|c|c|c|c|}
\hline & \multicolumn{2}{|c|}{ Old Course Structure } & \multicolumn{2}{|c|}{ New Course Structure } \\
\hline & Lecture Topic & Lab Topic & Lecture Topic & Lab Topic \\
\hline Week 1 & Course overview & Team activities & Course overview & Team activities \\
\hline Week 2 & $\begin{array}{l}\text { Engineering Design } \\
\text { Process (EDP) - All } \\
\text { details and design } \\
\text { tools presented }\end{array}$ & $\begin{array}{l}\text { Application of EDP } \\
\text { based on a simple design } \\
\text { challenge }\end{array}$ & $\begin{array}{l}\text { Overview of EDP \& } \\
\text { customer needs } \\
\text { identification \& } \\
\text { problem definition \& } \\
\text { background research }\end{array}$ & $\begin{array}{l}\text { Semester-long hands-on } \\
\text { design problem } \\
\text { introduction \& problem } \\
\text { definition \& background } \\
\text { research }\end{array}$ \\
\hline Week 3 & $\begin{array}{l}\text { Engineering models } \\
\text { with a focus on } \\
\text { technical drawing }\end{array}$ & $\begin{array}{l}\text { Technical drawing } \\
\text { practices }\end{array}$ & $\begin{array}{l}\text { Brainstorming } \\
\text { techniques }\end{array}$ & $\begin{array}{l}\text { Project brainstorming \& } \\
\text { minimum viable } \\
\text { prototypes }\end{array}$ \\
\hline Week 4 & $\begin{array}{l}\text { Introduction to } \\
\text { MATLAB }\end{array}$ & MATLAB tutorial & $\begin{array}{l}\text { Introduction to } \\
\text { MATLAB }\end{array}$ & MATLAB tutorial \\
\hline Week 5 & $\begin{array}{l}\text { Electrical } \\
\text { fundamentals }\end{array}$ & Electrical measurements & Engineering models & $\begin{array}{l}\text { Project experimenting } \\
\text { and modelling }\end{array}$ \\
\hline Week 6 & Motors and gears & $\begin{array}{l}\text { Motor characterization } \\
\text { and gear ratio effects }\end{array}$ & $\begin{array}{l}\text { Engineering decision } \\
\text { making and tools }\end{array}$ & Project decision making \\
\hline Week 7 & $\begin{array}{l}\text { Hands-on design } \\
\text { project introduction }\end{array}$ & $\begin{array}{l}\text { Project problem } \\
\text { definition \& } \\
\text { brainstorming }\end{array}$ & $\begin{array}{l}\text { Visual models - } \\
\text { technical drawing }\end{array}$ & $\begin{array}{l}\text { Technical drawing } \\
\text { practices }\end{array}$ \\
\hline Week 8 & Project management & $\begin{array}{l}\text { Project Gantt chart \& } \\
\text { brainstorming \& decision } \\
\text { making }\end{array}$ & Project management & $\begin{array}{l}\text { Project Gantt chart \& } \\
\text { technical drawing of } \\
\text { proposed design }\end{array}$ \\
\hline Week 9 & $\begin{array}{l}\text { Technical } \\
\text { communication }\end{array}$ & $\begin{array}{l}\text { Project proposal } \\
\text { presentations }\end{array}$ & $\begin{array}{l}\text { Technical } \\
\text { communication }\end{array}$ & $\begin{array}{l}\text { Project proposal } \\
\text { presentations }\end{array}$ \\
\hline Week 10 & Tools training & $\begin{array}{l}\text { Project construction \& } \\
\text { testing }\end{array}$ & Tools training & $\begin{array}{l}\text { Project construction \& } \\
\text { testing }\end{array}$ \\
\hline Week 11 & $\begin{array}{l}\text { Project related } \\
\text { topics }\end{array}$ & $\begin{array}{l}\text { Project construction \& } \\
\text { testing }\end{array}$ & Project testing & $\begin{array}{l}\text { Project construction \& } \\
\text { testing }\end{array}$ \\
\hline Week 12 & $\begin{array}{l}\text { Engineering } \\
\text { applications }\end{array}$ & $\begin{array}{l}\text { Project construction \& } \\
\text { testing }\end{array}$ & $\begin{array}{l}\text { Engineering } \\
\text { applications }\end{array}$ & $\begin{array}{l}\text { Project construction \& } \\
\text { testing }\end{array}$ \\
\hline Week 13 & $\begin{array}{l}\text { Cool engineering } \\
\text { design presentations }\end{array}$ & $\begin{array}{l}\text { Project construction \& } \\
\text { testing }\end{array}$ & $\begin{array}{l}\text { Cool engineering } \\
\text { design presentations }\end{array}$ & $\begin{array}{l}\text { Project construction \& } \\
\text { testing }\end{array}$ \\
\hline Week 14 & $\begin{array}{l}\text { Cool engineering } \\
\text { design presentations }\end{array}$ & $\begin{array}{l}\text { Project construction \& } \\
\text { testing }\end{array}$ & $\begin{array}{l}\text { Cool engineering } \\
\text { design presentations }\end{array}$ & $\begin{array}{l}\text { Project construction \& } \\
\text { testing }\end{array}$ \\
\hline Week 15 & Wrap-up & Project showcase & Wrap-up & Project showcase \\
\hline
\end{tabular}


Assessment and Results

To assess the impact of this new course structure on students' understanding of the engineering design process, students enrolled in the 6 sections of this course during the fall 2015 semester were considered the experimental group. Students enrolled in the same course taught by one of the authors during the spring 2015 semester using the old course structure were used as the control group. The assessment tool developed by Saterbak et al. ${ }^{27}$ was given to the control group toward the end of the spring semester after students have completed the design project as a take home exam. The same assessment tool was given to the experimental group once at the beginning of the fall semester before engineering design process was introduced and once toward the end of the semester after students have completed the design project as a take home exam. Students were asked to critique the flawed proposed engineering design process (shown in Figure 1) and they were instructed to focus on the following:

- Elaborate on the steps in the design process with specific details.

- Elaborate on specific strategies appropriate to accomplish the steps in the design process. Identify the pros (advantages, strengths, etc.) and cons (disadvantages, weaknesses, etc.) of the proposed design process.

\begin{tabular}{|c|c|c|c|c|c|c|c|c|c|c|c|c|c|c|}
\hline & \multicolumn{14}{|c|}{ Week } \\
\hline Activity: & 1 & 2 & 3 & 4 & 5 & 6 & 7 & 8 & 9 & 10 & 11 & 12 & 13 & 14 \\
\hline $\begin{array}{l}\text { Create many diff } \\
\text { concepts throug } \\
\text { brainstorming }\end{array}$ & & & & & & & & & & & & & & \\
\hline $\begin{array}{l}\text { Based on needs } \\
\text { most promising }\end{array}$ & & & & & & & & & & & & & & \\
\hline Build prototype & & & & & & & & & & & & & & \\
\hline $\begin{array}{l}\text { Test the prototy } \\
\text { needs are met }\end{array}$ & & & & & & & & & & & & & & \\
\hline $\begin{array}{l}\text { Make revisions } \\
\text { based on test re }\end{array}$ & & & & & & & & & & & & & & \\
\hline Build final desig & & & & & & & & & & & & & & \\
\hline Documentation & & & & & & & & & & & & & & \\
\hline
\end{tabular}

Figure 1. Gantt chart which shows the flawed proposed engineering design process ${ }^{27}$

Other than a two-page document which gives student the background information about Gantt charts, students were not allowed to use any other materials. In order to link responses from the pre- and post-assessment for the experimental group, students were asked to use anonymous usernames that were unique to each student (first two letters of their middle name, first two letters of their mother's maiden name and two numbers of the day they were born). All responses 
were coded based on the eight levels shown in Table 2, using a grading scale of $0,1,2$ for each level. A score of 0 was given if a student did not mention or comment on the step; 1 was given if a student mentioned the step but only in terms of time allotment or did not elaborate on it; and 2 was given if a student demonstrated thorough understanding of the step and provided specific details. The entire grading rubric can be found in Saterbak et al. ${ }^{27}$ and is also included in Appendix A. Each critique was individually coded according to the rubric. If there was any doubt regarding the appropriate coding of a response, the response was evaluated by both authors and consensus was achieved for the response in question. Example student responses representing each score for each coding category are given in Appendix B. These serve as representative responses that received each score, although some categories must be scored based on a holistic reading of the response in order to determine if they understand why each step is important. This is especially true of "Level 6: Overall Layout of a Design Process and Iteration".

Table 2. Grading of responses with 8 levels ${ }^{27}$

\begin{tabular}{|l|l|}
\hline Level & Topic \\
\hline Level 1 & Needs Assessment/Establishing Design Criteria \\
\hline Level 2 & Design Context Review \\
\hline Level 3 & Idea Generation \\
\hline Level 4 & Analysis and Decision Making \\
\hline Level 5 & Building and Testing \\
\hline Level 6 & Overall Layout of a Design Process and Iteration \\
\hline Level 7 & Time Allotments \\
\hline Level 8 & Documentation \\
\hline
\end{tabular}

Consent was obtained from all participants at the beginning of the fall 2015 semester (129 students provided consent and this corresponds to $\sim 62 \%$ response rate). Of those providing consent, only 96 completed both the pre- and post-tests. Only those who had both were included in this study ( $\sim 7 \%$ response rate) although there was no discernible difference between scores of those in this study and those who were not included. Because the spring 2015 semester was already completed without having them complete the consent form, consent was requested after the semester was over resulting in a very small sample for the spring 2015 cohort (7 students, $\sim 18 \%$ response rate). This limits our ability to make any definitive conclusions based on comparisons between semesters, although some statistically significant changes were observed. This cohort also did not take a pre-test and hence no conclusions can be drawn as to 
improvement caused by the structure of the class for the spring 2015 cohort. This is an area that may be addressed in future research.

Once all the responses were coded, the mean scores for each level were compared between the pre- and post-tests for the experimental group. A pairwise t-test was used to check for the statistical significance of any differences between the means. Results on all eight levels between the pre- and post-tests for the experimental group can be seen in Figure 2 and Figure 3 shows the total mean scores for the pre-and post-tests. All differences were significant with $\mathrm{p}$ values less than 0.0001 .

All levels showed an increase from the pre- test to post-test. This is consistent with the results observed by Saterbak et al. ${ }^{27}$, but the increases from this analysis were all statistically significant and more strongly significant (lower $\mathrm{p}$ values for most categories). The largest performance gains were seen in Levels 4 and 6 ("Analysis and Decision Making" and "Overall Layout of a Design Process and Iteration"). Levels 3-7 were at similar levels in the post-test with mean values around 1.6 showing that most students understood these aspects of the design process well. Again, these findings are in agreement with Saterbak et al., however, it should be noted that in general the post-test values in this study were lower than that of Saterbak et al. but still within a standard deviation of their results.

The only Level that was still weak (mean value less than 1) was Level 2 ("Design Context Review"). This is not something that has traditionally been emphasized in the class, but seems to be something to emphasize more in future offerings. This was also the level that was lowest for Saterbak et al. ${ }^{27}$ showing that this weakness is also observed by other researchers. It is somewhat surprising that the level with the smallest gain was Level 8 ("Documentation") since many students do not see this as valuable or forget about it coming into the course. Part of this small increase is due to the fact that the mean value from the pre-test is higher than expected. One reason for this higher than expected score in documentation is that the Gantt chart did include documentation as one of the tasks. This may have prompted students to at least comment on it rather than ignoring it. It is also surprising that more students did not comment on Level 1 ("Needs Assessment/Establishing Design Criteria") in the post-test since this was a major point of emphasis in the class and much time was spent during the project addressing problem definition and defining criteria and requirements for the problem. Part of this may be that students assumed that since the context of the project was given (namely they were told that the team was designing an examination table for a specific client) that this step was already completed (even though in the instructions it specifically stated that they are to assume that no prior work has been done on the project) and thus not mentioned. In fact, there were some students who did mention that they are making this assumption. It may also be that their understanding of problem definition and needs assessment does need improvement. Specifically, it was noticed that many students would mention that they needed to do this step without really mentioning the client or the role that the client plays in developing criteria. This can also be seen 
when students assume that the exact problem that needs to be solved will be given to them rather than using a prompt like this as the start of the problem investigation. Another cause could be due to the fact that the semester-long hands-on design project does not involve real clients that students could directly interact with, however, very similar results were seen by Saterbak et al. ${ }^{27}$ which did have real-world clients built into their project. This could be just an area of weakness in most first-year engineering students and ways of addressing this issue could be researched further in future studies. While there has been some work done to integrate clients into first-year courses (including the course studied by Saterbak et al. ${ }^{28-29}$ ), this is not feasible for many large institutions such as Arizona State University. In addition, Ernst et al. ${ }^{30}$ found little difference on design process knowledge when students were given an analysis-driven textbook design problem versus a design problem using real clients meaning that made-up clients could still possibly improve this level if appropriately implemented. For the course studied in this paper, even though interaction with clients was emphasized at the beginning of the project, students were not given the opportunity to directly interact with any stakeholders even though fictional stakeholders were created and their concerns were considered by students. There were a lot of details given in the documents which describe the design and so it is possible that students do not view these documents as representing clients wants/needs but just as another problem prompt. In future offerings of this course, the project given to students could be made more ambiguous so that students would be forced to think more about their clients and the questions they would like to ask them. Opportunities could be given to allow students to interact with the "clients" (modelled by instructors or TA's) in order to fully define the problem.

Overall, results indicate that the majority of the students started with little to no knowledge of the different Levels of the engineering design process at the beginning of this course and demonstrated significant improvement in their understanding at the end of the course, as can be seen in the overall improvement of the class' average total score (shown in Figure 3).

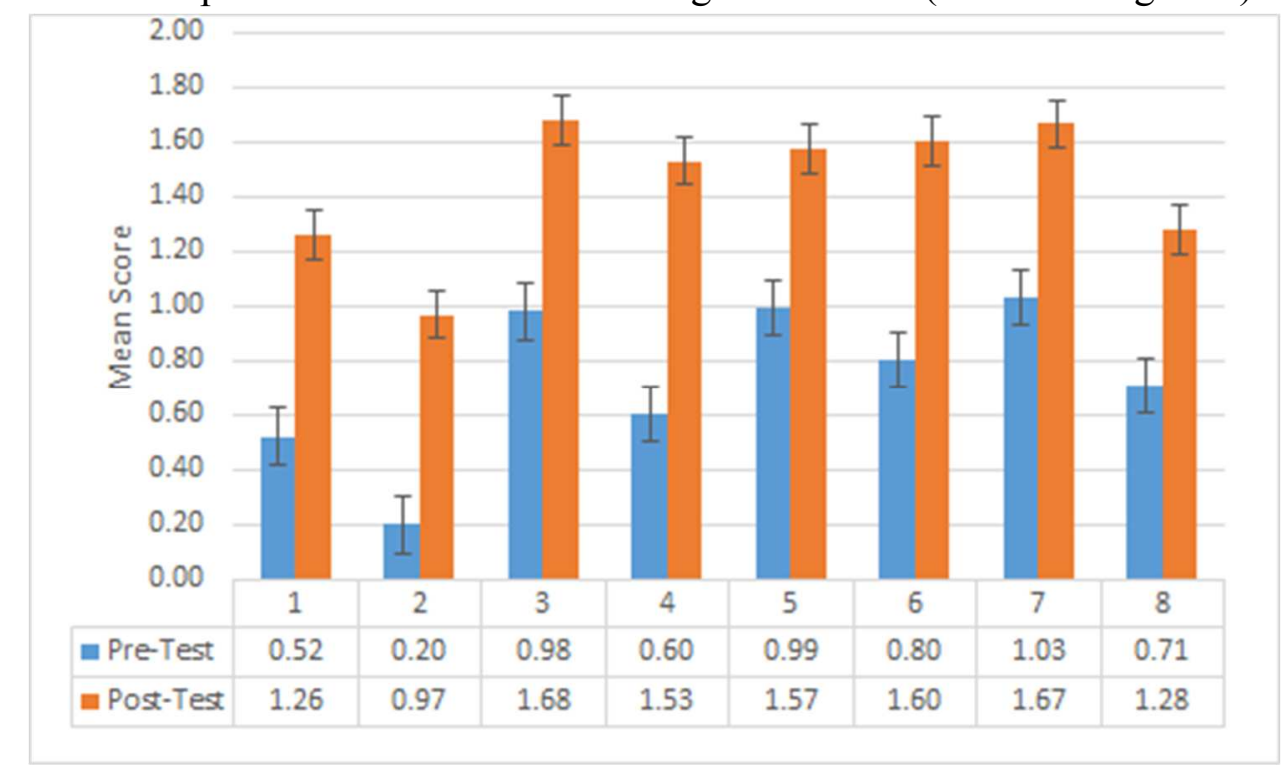

Figure 2. Experimental group pre- and post-test results comparison (mean scores at all 8 Levels) 


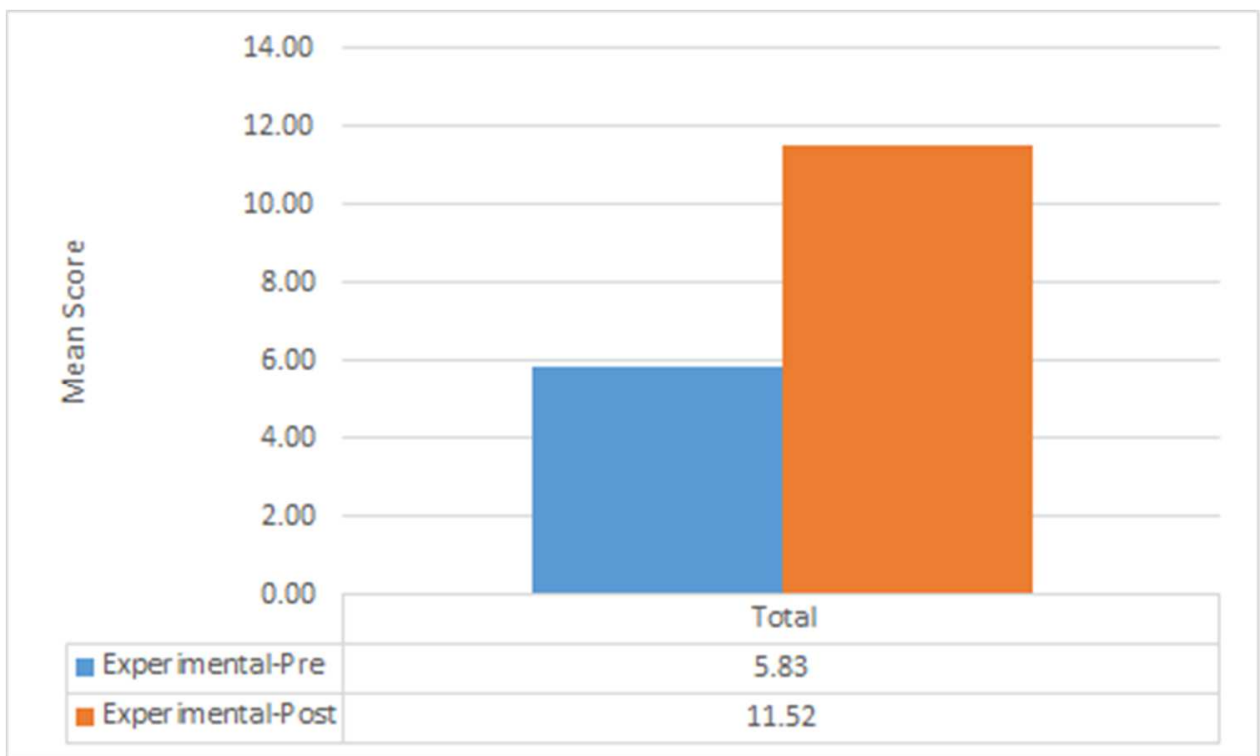

Figure 3. Experimental group pre- and post-test results comparison (total mean scores)

To assess the impact of the new structure on students' understanding of the engineering design process, mean scores on the post-tests between the experimental and the control groups are also compared (shown in Figures 4-5). Due to the small sample size of the control group, more work does need to be done to ensure that this sample is representative of the larger population and thus it is acknowledged that observed differences in this paper do need to be studied further using a larger control group. This will need to be addressed in future work. With that said, an independent t-test does show that the total mean scores are significantly different between the two groups and significant differences are also found at Levels 3 ("Idea Generation") and 5 ("Building and Testing"). This is not surprising as in the new course structure, an entire lecture was dedicated to ideation and students were given opportunities to practice different brainstorming techniques. They also had more time to apply the different brainstorming techniques in their project. On the other hand, with the old course structure, brainstorming rules and some techniques were just quickly introduced during the second week, along with many other topics and students had less than a lab to brainstorm for their project. Similarly, one entire lecture was used to introduce students to systematic testing and more thorough discussions about testing occurred with the new course structure.

Even though a statistically significant difference is not seen between the results for Level 4 ("Analysis and Decision Making"), it is interesting to note that in some of the responses from the experimental group, students mentioned the use of engineering models and analyses in the decision making stage but such comments were not found in any responses from the control group. For example, one of the participants mentioned: "Comparing the proposed solutions can be done with modelling, analysis, ...". 
For Level 8 ("Documentation"), a higher mean (though not statistically different) was found in the experimental group. This may be due to the fact that a more structured design notebook was required throughout the design process with the new course structure with each person being assigned a specific part of the notebook to complete each week.

Similar mean scores are found at Levels 1, 2, 6, and 7 between the two groups. This could be due to two possible reasons. For one, even though the new structure allowed students to spend more time at the beginning of the project, the same amount of time was given for project construction and testing and the same set of project deliverables were used to help students work through the engineering design process for both groups. In addition, both groups had the same opportunities to go through design iterations. For another, the low response rate (due to a delayed consent process) from the control group may have made the results unrepresentative.

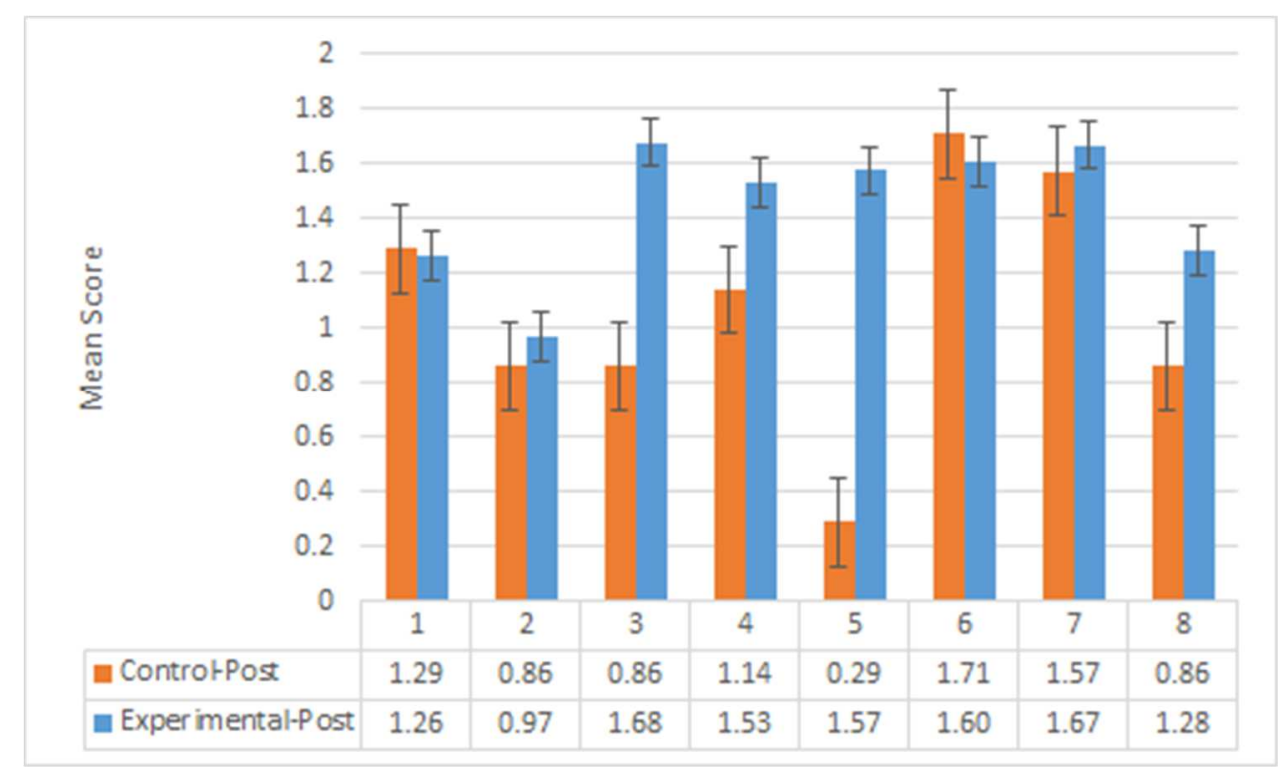

Figure 4. control and experimental groups post-test results comparison (mean scores at all 8 Levels) 


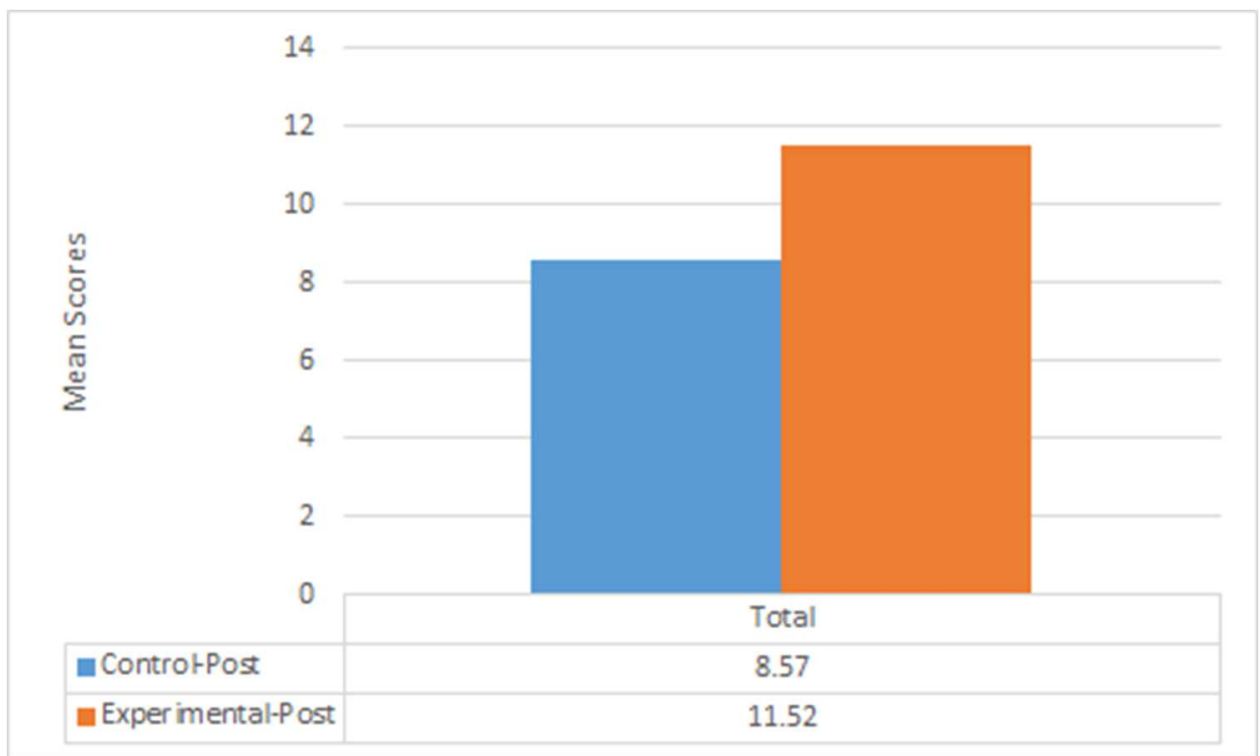

Figure 5. Control and experimental groups post-test results comparison (total mean scores)

Based on this data and observations by instructors, the change in structure did seem to help students better understand and apply the design process during their project. In the end of semester reflections, students were also asked what they learned about the engineering design process during the course of the semester. This data has not yet been coded, but it may prove useful for both validating the survey tool used in this study by correlating student perceptions of what they learned with demonstrated understanding based on the critiques. It may also help better understanding and interpret the results of this paper. This, however, is left for future work.

\section{Conclusion}

A new course structure has been implemented for the Introduction to Engineering course to teach the design and project concepts in the context of a semester-long hands-on design project. The new course structure provides more opportunities for just-in-time learning and an increased emphasis on a project with a higher level of student autonomy. This revised project based learning approach was implemented in order to increase student motivation to apply the fundamental design concepts and to improve their ability to apply them into other contexts. The impact of this new course structure on students' knowledge and application of the engineering design process has been assessed by asking students to critique a proposed flawed engineering design process for a 14-week project based on a validated assessment tool. Results show that the majority of students started the class with little to no knowledge of the engineering design process and have significantly improved their understanding of the design process at every level from identifying client need to the overall layout and characteristics of the design process. Significant improvement was also seen in students' understanding of the engineering design process, especially in areas such as idea generation, and building and testing, when comparing the results to those based on the old course structure, which focused on scaffolding and skill- 
building before implementing the skills and knowledge in a larger design project. Areas of improvement of the new course structure include more emphasis on needs assessment with client involvement as well as design context review.

The assessment tool has been found to be very effective at evaluating students' knowledge and application of the engineering design process. However, the authors feel that some improvements can be made to this tool. For example, less details could be provided for the 14-week project and more emphasis could be placed on the fact that no work was done prior to the construction of the Gantt chart which showed the flawed engineering design process. This could help minimize the confusion that the step "needs assessment and establishing design criteria" had already been completed. To avoid leading students to certain results in the rubrics based on more obvious things like one task taking significantly more time than others or suggesting tasks that they may not have considered otherwise, multiple Gantt charts could be provided with contrasting errors. Students could compare and contrast these Gantt charts rather than critiquing a single process. This may also help emphasize that they are not describing what a team has already done, but giving feedback on their plans with emphasis on choosing a process which will produce the best results. In addition, during the decision making stage, analysis and modelling should be included in the grading rubric as the engineering approach to designing is different from a hobbyist approach which focuses on 'trial and error'.

\section{References}

[1] S. Sheppard and R. Jennison, "Freshman engineering design experiences and organizational framework," International journal of Engineering Education, vol. 13, pp. 190-197, 1997.

[2] M. B. R. Vallim, J. M. Farines and J. E. R. Cury, "Practicing engineering in a freshman introductory course," Education, IEEE Transaction on, vol. 49, pp.74-79, 2006.

[3] J. Richardson and J. Dantzler, "Effect of a freshman engineering program on retention and academic performance," in Frontiers in Education, FIE 2002. 32nd Annual, 2002, pp. S2C-16-S2C-22 vol. 3, 2002.

[4] C. Dym, A. Agogino, O. Eris, D. Frey and Leifer, "Engineering design thinking, teaching, and learning,", Journal of Engineering Education, 94(1), pp103-120, 2005.

[5] S. D. Sheppard and J. Jenison, "Thoughts on freshman engineering design experiences," in Frontiers in Education Conference, 1996. FIE'96. 26th Annual Conference, the proceedings of, pp. 909-913 vol. 2 , 1996.

[6] M. Ohland, C. Brawner, M. Camacho, R. Layton, R. Long, S. Lord and M. Wasburn, "Race, gender, and measures of success in engineering education," Journal of Engineering Education, vol. 100, no. 2, pp. 225 $252,2011$. 
[7] M. Ohland, S. L. G. Sheppard, O. Eris, D. Chachra and A. Layton, "Persistence, engagement, and migration in engineering programs," Journal of Engineering Education, vol. 98, no. 3, pp. 259-278, 2008.

[8] N. Edward, "Evaluations of introducing project-based activities in the first and second years of engineering courses," European Journal of Engineering Education, vol. 29, no. 4, pp. 491-503, December 2004.

[9] W. A. Friess, "A first course in engineering design combining just-in-time CAD instruction within a horizontally integrated design project," in Frontiers in Education Conference (FIE), 2014 IEEE, pp.1-7, 22-25 Oct. 2014.

[10] M. J. Prince, R. M. Felder, "Inductive teaching and learning methods: definitions, comparisons, and research bases", Journal of Engineering Education, 95(2), pp123-138, 2006.

[11] C. Kim, J. Tranquillo, "K-wide: synthesizing the entrepreneurial mindset and engineering design", in American Society of Engineering Education, the proceedings of, Indianapolis, IN, 2014.

[12] M. Prince, "Does active learning work? A review of the research," Journal of Engineering Education, vol. 93, no. 3, pp. 1-10, 2004.

[13] E. de Graaff, and A. Kolmos, "Characteristics of problem-based learning", International Journal of Engineering Education, Vol. 19, No. 5, pp. 657-662, 2003.

[14] R. Welch, "How just in time learning should become the norm!", in American Society of Engineering Education, the Proceedings of, Louisville, KY, 2010.

[15] T. Grimm, "A just in time approach to teaching senior design", in American Society of Engineering Education, the Proceedings of, Nashville, TN, 2003.

[16] C. A. Estes, "Promoting student-centered learning in experiential education." Journal of Experiential Education 27(2), pp141-160, 2004.

[17] A. R. Carberry, H. Lee, and M.W. Ohland, "Measuring engineering design self-efficacy." Journal of Engineering Education, Vol. 99, pp.71-79, 2010.

[18] A. McKenna, P. Hirsch, "Evaluating student confidence in engineering design, teamwork and communication", in American Society of Engineering Education, the Proceedings of, Portland, OR, 2005.

[19] R. Bailey and Z. Szabo, "Validation of approaches to assess design process knowledge," in American Society of Engineering Education, the Proceedings of, Portland, OR, 2005.

[20] R. Adams, P. Punnakanta, C. J. Atman and C. D. Lewis, "Comparing design team self-reports with actual performance: cross-validating assessment instruments," in American Society for Engineering Education, the Proceedings of, Montreal, Canada, 2002.

[21] C. Atman, R. Adams, M. Cardella, J. Turns, S. Mosborg and J. Saleem, "Engineering design processes: a comparison of students and expert practitioners," Journal of Engineering Education, vol. 96, no. 4, pp. 359-379, 2007. 
[22] D. Crismond and R. Adams, "The informed design teaching and learning matrix," Journal of Engineering Education, vol. 101, no. 4, p. 738-797, 2012.

[23] C. Atman, D. Kilgore and A. McKenna, "Characterizing design learning: a mixed-methods study of engineering designers' use of language," Journal of Engineering Education, vol. 97, no. 3, pp. 309-326, 2008.

[24] D. Kilgore, C. Atman, K. Yasuhara, T. Barker and A. Morozov, "Considering context: a study of first-year engineering students," Journal of Engineering Education, vol. 96, no. 4, p. 321-334, 2007.

[25] R. Bailey and Z. Szabo, "Assessing engineering design process knowledge," International Journal of Engineering Education, vol. 22, no. 3, pp. 508-518, 2006.

[26] R. Bailey, "Effects of industrial experience and coursework during sophomore and junior years on student learning of engineering design," Transactions of the ASME, vol. 129, pp. 662-667, 2007.

[27] A. Saterbak, T. Volz, “Assessing knowledge and application of the design process in a first-year engineering design course", in American Society for Engineering Education Conference, Proceedings of, Indianapolis, IN, 2014.

[28] A. Saterbak, M. Embree and M. Oden, "Client-based projects in freshman design," in American Society of Engineering Education, the Proceedings of, San Antonio, TX, 2012.

[29] A. Saterbak and T. Volz, "Assessing design capabilities following a client-based freshman design course," in 4th First-Year Engineering Experience Conference, Pittsburgh, PA, 2012.

[30] N. Ernst, S. Brickley, R. Bailey, J. Cornia, "Effects of first-year engineering design course models on student design process knowledge," in Frontiers in Education Conference, 36th Annual, pp.7-12, 27-31 Oct. 2006.

\section{Appendix A. Assessment Tool Grading Rubric}

Level 1. Needs Assessment/Establishing Design Criteria. Explain why user needs must be gathered and that from these needs, design criteria need to be defined.

$0 \quad$ No mention of needs assessment or design criteria.

1 Mentions that a needs assessment should be done OR that design criteria should be established. (Notes that these steps are absent from chart.)

2 Mentions that user needs should be collected and that these drive the definition of design criteria.

Options 1 or 2 may mention that design criteria must be quantitative.

Level 2. Design Context Review. Explain why a design context review must be completed. $0 \quad$ No mention of design context review.

1 Mentions that a design context review must be done.

2 Mentions why and/or how a design context review is done. How research is done would include strategies such as research, understanding existing solutions, etc. 
Level 3. Idea Generation. Explain why multiple alternatives should be generated before developing a single alternative in depth.

$0 \quad$ No mention of idea generation or mention only in the context of time allocated (e.g., "Three weeks is enough time for brainstorming.")

1 Some mention of the activity of brainstorming

2 States that generating multiple ideas (brainstorming) is important and/or a valuable activity.

Option 2 may mention specific brainstorming methods, but this is not required.

Level 4. Analysis and Decision-Making. Explain that a combination of analysis and decisionmaking (based on the needs of the project) is required to select a few ideas before building them and analyze the completeness of approaches used in analysis and decision-making.

$0 \quad$ No mention of analysis or decision-making or mention only in the context of time allocated (e.g., "Six weeks is too long for selecting a concept.").

1 Mentions that decision-making on design criteria/user needs must be done.

2 Explains why decision-making on design criteria/user needs is important. OR. Mentions

that decision-making on design criteria/user needs must be done and mentions specific technique strategies, such as Pugh Screening or Scoring Matrices.

That the "selecting the most promising prototype" segment is too long should be captured under Level 7, Time Allocation.

Level 5. Building and Testing. Explain that built design should be tested to determine if they meet the needs.

$0 \quad$ No mention of building prototype or final design. No mention of testing.

1 Explains that built designs should be tested.

2 Explains that built designs should be tested to determine if they meet established design criteria/user needs.

Level 6. Overall Layout of a Design Process and Iteration. Explain the overall layout of a design process, including iteration.

$0 \quad$ No comment on overall layout of design process and iteration.

1 Some mention of the overall layout of design process and iteration. No specific examples or judgments made on strengths or weaknesses.

2 Clear, justified comments on the overall layout of design process. States that iteration occurs during design. Examples include:

a) Explains why building and design are iterative processes.

b) It is appropriate to overlap some activities on the Gantt chart.

c) Comments that the overall allocation of paper/built time is appropriate.

d) Brainstorming and redesign may follow failure at many points in the process. 
NOTE: This level must be read holistically. Does the student have a grasp of the overall process and an understanding that design is not a strictly linear process?

Level 7. Time Allotments. Analyze how much time is necessary for each step in a design process.

$0 \quad$ No mention of time allotments. Says that time allocation is correct.

1 States that time is not allocated well (without explaining where time is not allocated well)

2 Explains where time is not allocated well. Examples include:

a) "Selecting the most promising prototype" segment is too long.

b) Building the prototype should take longer than 1 week.

c) Building, testing, and revisions often overlap in their time frame.

d) Brainstorming time is $\mathrm{OK}$.

NOTE that extent of documentation is handled in Level 8.

Level 8. Documentation. Explain that documentation must occur through a design process.

0 No mention of documentation. States that the amount and placement of documentation is correct.

1 States that more documentation is needed. No specifics given on what should be documented or where in the process additional documentation should be done.

2 States that documentation is needed throughout the process.

\section{Appendix B. Representative Student Responses that Received Each Score at Each Level}

The table below shows sample student responses at each level that received a score of 2 or 1 .

Table B1. Student examples demonstrating the different scales used for each level

\begin{tabular}{|c|c|c|}
\hline Level & Score & Sample Responses \\
\hline Level 1 & 2 & $\begin{array}{l}\text { "The proposed design does not begin with defining the problem. Defining the problem is } \\
\text { the most important part of the project as this step determines the purpose and goals for the } \\
\text { project. As an engineer, knowing why something must be built is crucial for solving a } \\
\text { problem. Without a proper problem statement, there is no clear problem to solve, and thus, } \\
\text { there is no way to determine a best solution. } \\
\text { Additionally, the proposal does not include listing the design requirements and } \\
\text { constraints. Once the problem is clearly defined, the requirements of the design can be } \\
\text { listed. Listing the design requirements is necessary for selecting the best design concept. } \\
\text { This is the step that shapes the project as the project must always fit within these } \\
\text { requirements. If the project does fulfill these requirements than the project is considered a } \\
\text { failure. The constraints must also be defined as these are the factors that limit the project. } \\
\text { For example, if the budget for the project is } 100 \text { dollars and the proposed design will cost } \\
120 \text { dollars then the design cannot be built, as the resources are limited. } \\
\text { The project proposal also lacks a step for research. Proper research allows an } \\
\text { engineer to add to the project criteria. Research is learning more about the problem usually } \\
\text { by talking with the client to discuss the client's wants and needs. This further specifies the }\end{array}$ \\
\hline
\end{tabular}




\begin{tabular}{|c|c|c|}
\hline & & project criteria and requirements in order to build a better solution. " \\
\hline & 1 & $\begin{array}{l}\text { "To begin, I would give one week of data collection to the team so that they can } \\
\text { understand who they are creating a product for to best suit their lifestyle." }\end{array}$ \\
\hline \multirow[t]{2}{*}{ Level 2} & 2 & $\begin{array}{l}\text { "Gathering information through research will allow the team to know what has already } \\
\text { been done before with creating solutions for similar problems and give some ideas that can } \\
\text { be incorporated into what they make. Research can involve asking experts, reading } \\
\text { research papers, studying similar systems, etc." }\end{array}$ \\
\hline & 1 & $\begin{array}{l}\text { "But, before even considering beginning the brainstorming process, they must conduct } \\
\text { proper background research." }\end{array}$ \\
\hline \multirow[t]{2}{*}{ Level 3} & 2 & $\begin{array}{l}\text { "The most important aspect of brainstorming is that the quantity of ideas generated is far } \\
\text { more important than the quality of those ideas. Secondly, wild and crazy ideas are } \\
\text { encouraged. This is a very creative process and is not pointless even though you most } \\
\text { likely won't use these ideas because one crazy idea might spark the best idea yet. This } \\
\text { process is called hitchhiking, and building on each other's ideas is encouraged. Fourth, it's } \\
\text { important to not criticize any ideas. Brainstorming is highly effective in a collaborative } \\
\text { setting. The writing slip method allows for a large quantity of ideas, where each person is } \\
\text { drawing or writing concepts on cards quickly generating approximately } 40 \text { or more cards in } \\
15 \text { to } 20 \text { min per person. The group then passes the cards around allowing team input and } \\
\text { intentional hitchhiking. Morph charts (establish parameters and the correlating solutions) } \\
\text { and the SCAMPER method (substitute, combine, adapt, modify, put to other use, } \\
\text { eliminate, reverse), are two other examples of tools that can be used to make brainstorming } \\
\text { more effective and productive." }\end{array}$ \\
\hline & 1 & "Suggesting possible solutions for the problem by brainstorming method." \\
\hline \multirow[t]{2}{*}{ Level 4} & 2 & $\begin{array}{l}\text { "After a thorough brainstorming week, the next five weeks are dedicated to narrowing } \\
\text { down those ideas and choosing which idea would best fit the requirements and criteria for } \\
\text { the project. This is such an important part of the design process that it is given as much } \\
\text { time as the building and testing of the prototype itself. Taking the time to make sure that } \\
\text { the model being built is the best one is worth whatever time spent, but perhaps five weeks } \\
\text { is not needed. As part of this process, decision matrices and pairwise comparison charts } \\
\text { can be used to compare ideas. The pairwise comparison chart, or PCC, will help discover } \\
\text { the importance of each criterion compared to the others. Each criterion can then be } \\
\text { assigned a weight, to show that importance. The design matrices will show how the } \\
\text { designs compare with respect to certain criteria, and how the designs as a whole compare } \\
\text { based on the weighted totals of each criteria." }\end{array}$ \\
\hline & 1 & $\begin{array}{l}\text { "The second step is based on needs, select the most promising concept, which overlaps } \\
\text { during the first week of creating concepts and spans over six weeks. Out of the choices, the } \\
\text { Engineers Without Borders (EWB) team will select which ones on the concept } \\
\text { combination table best fit their need and combine different concepts to improve it." }\end{array}$ \\
\hline Level 5 & 2 & $\begin{array}{l}\text { "The Gantt chart provided allows for only one week of prototype construction, whereas it } \\
\text { may actually take longer than that to accomplish. In fact, the choosing of the design, as } \\
\text { time consuming as it may be, can be done in a week or two less than what is shown, and } \\
\text { more time can be allotted to the constructing of the prototype. More important than the } \\
\text { construction is the testing. Four weeks is a great amount of time to testing the examination } \\
\text { bed prototype, and still gives three weeks to go back and change and rebuild different } \\
\text { aspects of the bed after evaluation and before construction on the final project. Computer } \\
\text { programs such as MATLAB can be used to numerically represent the results of tests, and }\end{array}$ \\
\hline
\end{tabular}




\begin{tabular}{|c|c|c|}
\hline & & $\begin{array}{l}\text { different models, such as mathematical, computational, visual, or material models can be } \\
\text { created to demonstrate the effectiveness of different aspects of the design. } \\
\text { Testing is such a vital part of the engineering design process, as it ensures that the product } \\
\text { will meet the requirements and criteria that were set for the project. It allows time to } \\
\text { evaluate what changes may need to occur and what differences may need to be present in } \\
\text { the final model." }\end{array}$ \\
\hline & 1 & $\begin{array}{l}\text { "The test section is also unclear. There are no specific test, and there is no definition as to } \\
\text { what part of the prototype is going to be tested or if the prototype will be tested as a whole. } \\
\text { Thus, one would be unable to determine the success of a project, without a proper test } \\
\text { explaining what is being tested, and since the problem is not defined, there is no way to } \\
\text { show whether a prototype is successful or not." }\end{array}$ \\
\hline \multirow[t]{2}{*}{ Level 6} & 2 & $\begin{array}{l}\text { "The engineering design process is an iterative process as opposed to a linear process. } \\
\text { Within the design process the various stages can occur simultaneously, shortcuts can be } \\
\text { taken to different stages, and the process can also go in reverse." }\end{array}$ \\
\hline & 1 & $\begin{array}{l}\text { "Usually it is not uncommon for things to turn out differently than expected or unforeseen } \\
\text { hindrances that occur no matter how prepared the group is and they left little time to } \\
\text { actually be put within the building process. However, one way to further speed up the } \\
\text { building process is to separate the work amongst team members depending on experiences, } \\
\text { skill, and other expertise." }\end{array}$ \\
\hline \multirow[t]{2}{*}{ Level 7} & 2 & $\begin{array}{l}\text { "Time is distributed in a very ineffective way } \\
\circ \text { More time should be spent brainstorming than selecting a concept } \\
\circ \text { More time should be allotted to building prototypes } \\
\circ \text { Building and testing prototypes, as well as revising the final design should have a fluid } \\
\text { timeframe i.e., as a prototype is built, test it and revise and then make a new prototype } \\
\circ \quad \text { The timeframe given for building the final design is not proportional to the rest of the } \\
\text { chart" }\end{array}$ \\
\hline & 1 & "In addition, some of the tasks were given unreasonable amount of time." \\
\hline \multirow[t]{2}{*}{ Level 8} & 2 & $\begin{array}{l}\text { "[Documentation] should be taking place throughout the entire design process. The } \\
\text { documentation should represent why design decisions were made, include all ideas, } \\
\text { different designs, test and the results. If the documentation is done properly, it should } \\
\text { allow someone to understand the team's train of thought throughout the process and their } \\
\text { methodology behind their design. It should keep track of the entire design process, and } \\
\text { allows this design to be reproducible. By doing this, the team can reflect on where they } \\
\text { might have made some errors and so on." }\end{array}$ \\
\hline & 1 & $\begin{array}{l}\text { "Documentation is also highly important in the design process. It allows you to refer back } \\
\text { to previous results, ideas, and even changes that were made throughout the process." }\end{array}$ \\
\hline
\end{tabular}

